\section{МОЛЕКУЛЯРНО-ГЕНЕТИЧЕСКИЙ АНАЛИЗ АССОЦИАЦИЙ КОМБИНАЦИЙ ПОЛИМОРФНЫХ ВАРИАНТОВ ГЕНОВ СИСТЕМЫ БИОТРАНСФОРМАЦИИ КСЕНОБИОТИКОВ С РАЗВИТИЕМ ИЗОЛИРОВАННОГО ДЕФЕКТА МЕЖЖЕЛУДОЧКОВОЙ ПЕРЕГОРОДКИ В КРАСНОДАРСКОМ КРАЕ}

Федеральное государственное бюджетное образовательное учреждение высшего образования «Кубанский государственный медицинский университет», ул. Митрофана Седина, д. 4, г. Краснодар, 350063, Российкая Федерация Автор для переписки: К.Ю. Лазарев (lazarev_ku@mail.ru)

Информация для цитирования: Лазарев К.Ю., Брайко О.П. Молекулярногенетический анализ ассоциаций комбинаций полиморфных вариантов генов системы биотрансформации ксенобиотиков с развитием изолированного дефекта межжелудочковой перегородки в Краснодарском крае // Научные результаты биомедицинских исследований. 2018. Т. 4, N 3. С. 18-27. [Lazarev $\mathrm{KY}$, Brayko OP. Molecular-genetic analysis of associations of polymorphous genes combinations of the xenobiotics biotransformation with the isolated ventricular septal defect development in the Krasnodar territory. Research Results in Biomedicine. 2018;4(3):18-27 (In Russian)]. DOI: 10.18413/2313-8955-2018-4-3-0-2

\begin{abstract}
Аннотация
Актуальность: Изучение вовлеченности полиморфизма генов-кандидатов системы биотрансформации ксенобиотиков в формирование врожденных пороков развития у детей является одной из актуальных задач современной медицины. Цель исследования: Определить ассоциации комбинаций полиморфизмов генов системы биотрансформации ксенобиотиков с предрасположенностью формирования дефекта межжелудочковой перегородки (ДМЖП) у детей в Краснодарском крае. Материалы и методы: В исследование включены дети с верифицированным ДМЖП (100 человек), средний возраст $3.11 \pm 0.81$ лет. Группой популяционного контроля явились родители детей с ДМЖП, не имеющие врожденных пороков развития. Все исследуемые имели славянскую национальность и являются коренными жителями Краснодарского края. Проведены выделение ДНК и амплификация полиморфизмов генов в режиме реального времени; проведен анализ полученных генотипов при помощи метода дискриминации аллелей. Для оценки соответствия распределений генотипов ожидаемым значениям при равновесии Харди-Вайнберга и для сравнения распределений частот генотипов и аллелей в выборке больных и здоровых использовали критерий $\chi^{2}$. Результаты: Показана статистическая достоверность 5 комбинаций генотипов, имеющих повышенный риск формирования ДМЖП: CYP1B 1432AA х NAT2 590GG, CYP1B1 432GG x CYP3A4 664TT, CYP3A4 664TT x CYP3A5 6986AA для лиц мужского пола, CYP1B1 432AG х NAT2 590AA, CYP2C9 $1075 \mathrm{AC}$ х CYP3A4 664TC - для лиц женского пола, с показателями $(\mathrm{p}<0.05, \mathrm{OR}=3.29,95 \%$
\end{abstract}


$\mathrm{CI}=1.11-9.74),(\mathrm{p}<0.05, \mathrm{OR}=14.23,95 \% \mathrm{CI}=1.72-117.86),(\mathrm{p}<0.05, \mathrm{OR}=4.75,95 \%$ $\mathrm{CI}=0.98-23.10),(\mathrm{p}<0.05, \mathrm{OR}=2.66,95 \% \mathrm{CI}=0.95-7.41),(\mathrm{p}<0.05, \mathrm{OR}=7.07,95 \%$ $\mathrm{CI}=0.77-64.83)$ соответственно и 3 комбинации протективного характера NAT2 590GA x ABCB1 3435CT $(\mathrm{p}<0.05, \mathrm{OR}=0.37,95 \% \mathrm{CI}=0.15-0.94), C Y P 1 B 1432 \mathrm{AA}$ x CYP2C9 1075AA (p<0.05, OR=0.40, 95\% CI=0.17-1.00) - для лиц мужского пола, СYР2C9 1075AC х CYP3A56986AA (p<0.05, OR=0.36, 95\% CI=0.13-1.03) для лиц женского пола. Заключение: Установлены 8 парных сочетаний генотипов ферментов биотрансформации ксенобиотиков, ассоциированных с риском развития изолированного дефекта межжелудочковой перегородки.

Ключевые слова: врожденный дефект межжелудочковой перегородки (ДМЖП); ферменты биотрансформации ксенобиотиков (ФБК); полиморфизм; маркер предрасположенности; Краснодарский край

\title{
MOLECULAR-GENETIC ANALYSIS OF ASSOCIATIONS OF POLYMORPHOUS GENES COMBINATIONS OF THE XENOBIOTICS BIOTRANSFORMATION WITH THE ISOLATED VENTRICULAR SEPTAL DEFECT DEVELOPMENT IN THE KRASNODAR TERRITORY
}

\author{
Kuban State Medical University, \\ 4 Mitrofan Sedin St., Krasnodar, 350063, Russia \\ Corresponding author: Konstantin Yu. Lazarev (lazarev_ku@mail.ru)
}

\begin{abstract}
Background: The study of the involvement of polymorphisms of candidate genes of the biotransformation system of xenobiotics in the formation of congenital malformations in children is one of the urgent problems of modern medicine. The aim of the study: To estimate the polymorphous genes associations of the xenobiotic biotransformation system with ventricular septal defect predilection in children in Krasnodar region. Materials and methods: Children with verified VSD (100 participants), mean age $3.11 \pm 0.85$, were tested in the research. The parents (without congenital minimum effective temperature) of children with VSD were tested as a population group. The participants were the innates of the Krasnodar Territory and belonged to the Slavic nationality. The DNA and polymorphous genes amplification were made in the real time mode; the derived genotypes were analysed by the alleles' discrimination method. The $\mathrm{x}^{2}$ criterion, for concordance estimation genotypes distribution of expected meanings by Hardy- Weinberg equilibrium and for the comparison of frequency genotypes and alleles distribution (among healthy and diseased patients), were used. Results: The statistical validity (having high risk of VSD formation) of 5 genotypes combinations was revealed: CYP1B 1432AA x NAT2 590GG, CYP1B1 432GG x CYP03A4 664TT, CYP3A4 664TT x CYP3A5 6986AA - male gender, CYP1B1 432AG x NAT2 590AA, CYP2C9 1075AC x CYP3A4 664TC - female gender, with indices $(\mathrm{p}<0.05$, OR $=3.29,95 \% \mathrm{CI}=1.11$ 9.74), $(\mathrm{p}<0.05, \mathrm{OR}=14.23,95 \% \mathrm{CI}=1.72-117.86),(\mathrm{p}<0.05, \mathrm{OR}=4.75,95 \% \mathrm{CI}=0.98-$ 23.10), $(\mathrm{p}<0.05, \mathrm{OR}=2.66,95 \% \mathrm{CI}=0.95-7.41),(\mathrm{p}<0.05, \mathrm{OR}=7.07,95 \% \mathrm{CI}=0.77-$ 64.83 ), including 3 combinations of protective character NAT2 590GA x ABCB1 $3435 \mathrm{CT} \quad(\mathrm{p}<0.05, \quad \mathrm{OR}=0.37,95 \%$ CI $=0.15-0.94), C Y P 1 B 1$ 432AA x CYP2C9
\end{abstract}


1075AA $(\mathrm{p}<0.05, \mathrm{OR}=0.40,95 \% \mathrm{CI}=0.17-1.00)-$ male gender, $C Y P 2 C 91075 \mathrm{AC} \mathrm{x}$ CYP3A56986AA $\quad(\mathrm{p}<0.05, \quad \mathrm{OR}=0.36, \quad 95 \% \quad \mathrm{CI}=0.13-1.03) \quad-$ female gender. Conclusion: Eight pairs of combinations of genotypes of xenobiotic biotransformation enzymes associated with the risk of developing an isolated defect of the interventricular septum were established.

Keyword: congenital ventricular septal defect (VSD); enzymes of xenobiotics biotransformation (EXB); polymorphism; predilection marker; Krasnodar region

Введение. Врожденные пороки сердца являются актуальной медико-социальной проблемой со значительным колебанием показателей распространенности как в различных странах мира, так и в регионах Российской Федерации (3.17-8.00\%) $[1,2,3]$. ВПС составляют незначительный удельный вес в общей заболеваемости детей (2\%). Однако вклад ВПС в формирование младенческой смертности и детской инвалидности более значителен. В Российской Федерации зарегистрированы около 25.7 тыс. детей-инвалидов по причине ВПС, из них $40.9 \%$ в возрасте от 0 до 4 лет, $10.3 \%$ - 15-17-летних [4].

Изолированные случаи дефекта межжелудочковой перегородки (ДМЖП) занимает лидирующее положение в структуре врожденных пороков развития системы кровообращения (ВПР СК) в Краснодарском крае $(51.8 \%)$ с частотой среди новорожденных 7.96\% [5] и имеют мультифакториальную природу. На сегодняшний день накоплено значительное число данных научной литературы свидетельствуют в пользу вовлеченности различных полиморфных генов в формирование предрасположенности к патологии мультифакториального генеза. Именно гены ферментов детоксикации ксенобиотиков, экспрессия которых зависит от внешне-средовых факторов и участвуют в развитии предрасположенности к формированию ДМЖП, и представляют собой интерес для исследований этиологии мультифакториальных заболеваний $[6,7,8$, 9, 10]. В связи с этим, представляется целесообразным тестирование полиморфных вариантов Val432Leu CYP1B1, G590A NAT2, 3435T ABCB1, A1075C CYP2C9,
T664C CYP3A4, +6986G/A CYP3A5 в качестве маркеров предрасположенности к формированию ДМЖП.

Цель работы - определить ассоциации полиморфизмов Val432Leu CYP1B1, G590A NAT2, 3435T ABCB1, A1075C CYP2C9, T664C CYP3A4, +6986G/A CYP3A5 с предрасположенностью к ДМЖП у детей Краснодарского края.

Материалы и методы исследования. Основным объектом настоящего исследования явились дети с ДМЖП (100 человек), родившиеся в 1998-2012гг из 38 территориальных образований и 6 городов Краснодарского края. Средний возраст детей с ДМЖП составил $3.11 \pm 0.81$ лет (46 мальчиков $-46 \%$ и 64 девочки - 64\%). Группой популяционного контроля явились родители детей с ДМЖП, не имеющие врожденных пороков развития, также славянской национальности и являющиеся коренными жителями Краснодарского края.

Для систематизации и статистической обработки данных была сформирована электронная база с включенными сведениями каждого пробанда.

С целью верификации диагноза всем больным было проведено комплексное обследование, включающее клинические методы с использованием физикального обследования, анкетирования, и специальные (ЭКГ, УЗИ, рентгенографии сердца и др.), а также клиникогенеалогический, цитогенетический методы исследования.

ДНК выделяли из замороженной крови стандартным методом фенольнохлороформной экстракции. Анализ полиморфизмов генов ферментов биотрансформации ксенобиотиков осуществляли мето- 
дом полимеразной цепной реакции с соответсвующим анализом данных в амплификаторе CFX96 Bio-rad и Rotor Gene Q5 plex HRM (Qiaqen) в режиме Real time с использованием полимеразы Thermus aquaticus (Таq-полимераза), производства фирмы «СибЭнзим», олигонуклеотидных прайме- ров и зондов, синтезированных фирмой «Синтол» (таблица 1) с дальнейшим проведением ПЦР и анализированием полученных генотипов при помощи метода дискриминации аллелей. Ход протоколов изучаемых полиморфизмов представлен в таблице 2.

\section{Праймеры и зонды, примененные для типирования ДНК-маркеров методом Taq Man зондов в режиме Real Time}

Таблица 1

\section{Table 1}

Primers and probes used for typing DNA markers using the Taq Man probes method in Real Time mode

\begin{tabular}{|c|c|c|c|}
\hline Ген & Полиморфизм & Структура праймеров и зондов & Источник \\
\hline$C Y P 1 B 1$ & Val432Leu & $\begin{array}{l}\text { F: 5'- tgt caa cca gtg gtc tgt gaa tc }-3^{\prime} \\
\text { R: 5'- tca ctc tgc tgg tca ggt cct t }-3^{\prime} \\
\text { 5'-FAM-accca(g-LNA)tgaagtgg-RTQ1-3' } \\
\text { 5'-ROX-atgaccca(c-LNA)tgaagtg-BHQ2-3' }\end{array}$ & {$[11]$} \\
\hline$N A T 2$ & G590A & $\begin{array}{l}\text { F: 5'- ctgccaaagaagaaacaccaaaa -3' } \\
\text { R: 5'- tggagacgtctgcaggtatgtatt -3' } \\
\text { 5'-FAM- acctc(g-LNA)aacaattg-RTQ1-3', } \\
\text { 5'-ROX-tgaacctc(a-LNA)aacaatt-BHQ2-3' }\end{array}$ & {$[12]$} \\
\hline$A B C B 1$ & C3435T & $\begin{array}{l}\text { F: 5'- ctgtttgactgcagcattgct -3' } \\
\text { R: 5'- atgtatgttggectcctttgct -3' } \\
\text { 5'-FAM-ccctcac(a-LNA)atctctt-RTQ1-3' } \\
\text { 5'-ROX-ccctcac(g-LNA)atctctt-BHQ2-3' }\end{array}$ & {$[8]$} \\
\hline$C Y P 2 C 9$ & A1075C & $\begin{array}{l}\text { F: 5'- gccacatgccctacacagatg -3' } \\
\text { R: 5'- gaatttaatgtcacaggtcactgcat -3' } \\
\text { 5'-FAM-aaggtcaa(g-LNA)gtatctc-RTQ1-3, } \\
\text { 5'-ROX- aggtcaa(t-LNA)gtatctct-BHQ2-3' }\end{array}$ & [13] \\
\hline CYP3A4 & T664C & $\begin{array}{l}\text { F: 5'- tggaatgaggacagccatagaga -3' } \\
\text { R: 5'- agtggagccattggcataaaatct -3' } \\
\text { 5'-FAM-aagggca(g-LNA)gagagag-RTQ1-3' } \\
\text { 5'-ROX-aagggca(a-LNA)gagagag-BHQ2-3' }\end{array}$ & [14] \\
\hline CYP3A5 & $+6986 \mathrm{G} / \mathrm{A}$ & $\begin{array}{l}\text { F: 5' - tgaagggtaatgtggtccaaacag -3' } \\
\text { R: 5'- cgaatgctctactgtcatttctaacca -3' } \\
\text { 5'-FAM- tttgtctttca (a-LNA)tatctc-RTQ1-3' } \\
\text { 5'-ROX-ttttgtctttca (g-LNA)tatctc-BHQ2-3, }\end{array}$ & {$[14]$} \\
\hline
\end{tabular}


Таблица 2

\section{Протоколы генотипирования}

Table 2

Protocols of genotyping

\begin{tabular}{|c|c|c|}
\hline $\begin{array}{c}\text { Ген, } \\
\mathrm{t}^{0} \text { отжига }\end{array}$ & $\begin{array}{c}\text { Полимор- } \\
\text { физм }\end{array}$ & Профиль \\
\hline $\begin{array}{c}\text { CYP1B1 } \\
48^{\circ} \mathrm{C}\end{array}$ & Val432Leu & $\begin{array}{l}\text { Смесь реакционных компонентов объемом } 25 \text { мкл из расчета на } \\
1 \text { образец включает: бидистиллированная деионизированная вода } \\
18.1 \text { мкл, ионы магния } 2.5 \text { мкл, буфер } 2.5 \text { мкл, дезоксирибонукле-- } \\
\text { зидфосфаты (dATP, dGTP, dCTP, dTTP) } 0.4 \text { мкл, праймер F } 0.1 \text { мкл, } \\
\text { праймер R } 0.1 \text { мкл, зонд FAM 0.05мкл, зонд ROX } 0.05 \text { мкл, }\end{array}$ \\
\hline $\begin{array}{l}\text { NAT2 } \\
45^{\circ} \mathrm{C}\end{array}$ & G590A & $\begin{array}{l}\text { Tаq-полимераза } 0.2 \text { мкл, ДНК } 1 \text { мкл. } \\
\text { Процесс генотипирования проводился при помощи метода } \\
\text { Таq Мап зондов по изменению уровня относительной флуоресценции } \\
\text { используемых зондов (величины RFU) на амплификаторе с флюо рес- }\end{array}$ \\
\hline $\begin{array}{l}\mathrm{ABCB} 1 \\
51.3^{\circ} \mathrm{C}\end{array}$ & C3435T & $\begin{array}{l}\text { Центной детекцией } \\
\text { По окончании первого этапа - денатурации при } 95{ }^{\circ} \mathrm{C} \text { с временем } \\
\text { экспозиции } 5 \text { минут осуществлялось } 40 \text { непрерывных циклов ампли- } \\
\text { фикации, включающих отжиг праймеров в течение } 60 \text { секунд при } \\
45-51.3^{\circ} \mathrm{C} \text { и денатурация в течение } 15 \text { сек при } 95^{\circ} \mathrm{C} .\end{array}$ \\
\hline $\begin{array}{c}\text { CYP2C9 } \\
45^{\circ} \mathrm{C}\end{array}$ & $\mathrm{A} 1075 \mathrm{C}$ & $\begin{array}{l}\text { Смесь реакционных компонентов объемом } 25 \text { мкл из расчета на } \\
1 \text { образец включает: бидистиллированная деионизированная вода } \\
\text { 17.1мкл, ионы магния } 2.5 \text { мкл, буфер } 2.5 \text { мкл, дезоксирибонуклео- } \\
\text { зидфосфаты (dATP, dGTP, dCTP, dTTP) } 0.4 \text { мкл, праймер F } 0.1 \text { мкл, } \\
\text { праймер R } 0.1 \text { мкл, зонд FAM } 0.05 \text { мкл, зонд ROX } 0.05 \text { мк, }\end{array}$ \\
\hline $\begin{array}{c}C Y P 3 A 4 \\
45^{\circ} \mathrm{C}\end{array}$ & T664C & $\begin{array}{l}\text { Tаq-полимераза } 0.2 \text { мкл, ДНК } 2 \text { мкл. } \\
\text { Процесс генотипирования проводился при помощи метода Taq } \\
\text { Мап зондов по изменению уровня относительной флуоресценции ис- } \\
\text { пользуемых зондов (величины RFU) на амплификаторе с флюорес- } \\
\text { центной детекцией Rotor Gene Q } 5 \text { plex HRM (Qiaqen). }\end{array}$ \\
\hline $\begin{array}{c}C Y P 3 A 5 \\
45^{\circ} \mathrm{C}\end{array}$ & $+6986 \mathrm{G} / \mathrm{A}$ & $\begin{array}{l}\text { По окончании первого этапа - денатурации при } 95^{\circ} \mathrm{C} \text { с временем } \\
\text { экспозиции } 5 \text { минут и удержанием температуры } 5 \text { сек при } 72{ }^{\circ} \mathrm{C} \text {, осу- } \\
\text { ществлялось } 40 \text { непрерывных циклов амплификации, включащих } \\
\text { отжиг праймеров в течение } 60 \text { секунд при } 45^{\circ} \mathrm{C} \text { и денатурация в тече- } \\
\text { ние } 15 \text { сек при } 95^{\circ} \mathrm{C} \text {. }\end{array}$ \\
\hline
\end{tabular}

Для оценки соответствия распределений генотипов ожидаемым значениям при равновесии Харди-Вайнберга и для сравнения распределений частот генотипов и аллелей в выборке больных и здоровых использовали критерий $\chi^{2}$ [15]. Уровень статистической значимости различий между группами принимали $\mathrm{p} \leq 0.05$. Об ассоциации аллелей и генотипов с предрасположенностью к ДМЖП судили по величине отношения шансов (OR) [13]. Границы 95\%-го доверительного интервала (CI) для OR вычисляли методом B. Woolf. Уровень статистической значимости для D - показатель, от- ражающий различия между наблюдаемыми и ожидаемыми отношениями гаплотипов специфических аллелей двух локусов при нулевой гипотезе $\left(\mathrm{H}_{0}\right)$ о независимости их наследования рассчитывали с помощью критерия $\chi^{2}$ для таблиц сопряженности $2 \times 2$ [16].

Результаты и их обсуждение. Анализ распределения генотипов изучаемых полиморфных генов Val432Leu CYP1B1, G590A NAT2, 3435T ABCB1, A1075C CYP2C9, T664C CYP3A4, +6986G/A CYP3A5 показал, что эмпирическое распределение генотипов соответствует теоретически ожидаемому 
при равновесии Харди-Вайнберга (>0.05), но эмпирическое распределение генотипов G590A NAT2 не соответствует теоретически ожидаемому в связи с уменьшением фактического уровня гетерозиготности $(\mathrm{p}<0.05)$. Уровень аллельного разнообразия по данным локусам составил $\mathrm{H}_{0}=0.49$ (для локуса Val432Leu CYP1B1), $\mathrm{H}_{0}=0.35$ (для локуса G590A NAT2), $\mathrm{H}_{0}=0.45$ (для локуса С $3435 \mathrm{~T}$ $A B C B 1$ ), $\mathrm{H}_{0}=0.49$ (для локуса $\mathrm{A} 1075 \mathrm{C}$ CYР2C9), $\mathrm{H}_{0}=0.35$ (для локуса Т664C CYP3A4), $\mathrm{H}_{0}=0.45$ (для локуса $+6986 \mathrm{G} / \mathrm{A}$ CYP3A5) среди индивидуумов с ДМЖП и $\mathrm{H}_{0}$ $=0.49$ (для локуса Val432Leu CYP1B1), $\mathrm{H}_{0}=0.41$ (для локуса G590A NAT2), $\mathrm{H}_{0}=0.53$ (для локуса С $3435 \mathrm{~T} A B C B 1$ ), $\mathrm{H}_{0}=0.17$ (для локуса $\mathrm{A} 1075 \mathrm{C} C Y P 2 C 9$ ), $\mathrm{H}_{0}=0.13$ (для локуса Т664C CYP3A4), $\mathrm{H}_{0}=0.14$ (для локуса +6986G/A СYР3А5) в популяционной выборке.

Статистически значимых различий в частотах аллелей изучаемых полиморфных вариантов генов ФБК между группами больных ДМЖП и здоровых не установлено $(\mathrm{p}>0.05)$, но наблюдается протективное накоплению аллеля 664C CYP3A4 в группе здоровых $(0,070)$ в отличие от больных
ДМЖП (0.030) $\quad(\mathrm{p}=0.05, \quad \mathrm{OR}=0.41, \quad 95 \%$ $\mathrm{CI}=0.16-1.04)$.

При сравнительном анализе частот генотипов исследуемых полиморфизмов генов ФБК в группе больных ДМЖП и здоровых индивидов статистически значимых различий не установлено ( $>>0.05)$, установлено протективное накоплением генотипов 664TТ CYP3A4 и 664TC CYP3A4 в отношении риска развития ДМЖП $\left(\chi^{2}=3.99, \quad p=0.05, \quad\right.$ OR $=0.39,95 \% \quad \mathrm{CI}=0.15$ $1.01)$.

Данные анализа парных сочетаний генотипов исследуемых полиморфизмов приведены в сводной таблице 3 . Выявлены 3 комбинации, ассоциированные с повышенным риском развития ДМЖП: CYP1B1 432GG x NAT2 590GA, CYP1B1 432AA x ABCB1 3435TT, CYP3A4 664TT x СУР3А5 6986АA для которых были установлены статистически значимые различия $(\mathrm{p}<0.05, \mathrm{OR}=2.81,95 \% \mathrm{CI}=1.06$ $7.39),(\mathrm{p}<0.05, \mathrm{OR}=2.4195 \% \mathrm{CI}=1.07-5.43)$, $(\mathrm{p}<0.05, \quad \mathrm{OR}=2.53,95 \% \mathrm{CI}=1.14-5.59)$ и 1 протективная CYP2C9 1075AA х CYP3A4 $664 \mathrm{TC}(\mathrm{p}<0.05, \mathrm{OR}=0.22,95 \% \mathrm{CI}=0.05-0.97)$ соответственно.

Таблица 3

Распределение частот парных сочетаний генотипов генов ФБК в группах больных ДМЖП и здоровых индивидов (абс, \%)

\section{Frequency distribution of paired combinations of genotypes of FBK genes in groups of patients} with VSD and healthy individuals (abs, \%)

\begin{tabular}{|l|c|c|c|c|}
\hline \multicolumn{1}{|c|}{ Комбинации генотипов } & $\begin{array}{c}\text { Больные } \\
\text { ДМЖП } \\
(\mathrm{n}=100)\end{array}$ & $\begin{array}{c}\text { Контроль } \\
(\mathrm{n}=150)\end{array}$ & $\begin{array}{c}\text { Критерий } \\
\text { различия } \\
\chi^{2}(\mathrm{p})\end{array}$ & $\begin{array}{c}\text { OR } \\
(95 \% \mathrm{CI})\end{array}$ \\
\hline CYP1B1 432GG x NAT2 590GA & $3(3.0)$ & $7(4.6)$ & $4.66(0.03)^{*}$ & $2.81(1.06-7.39)$ \\
\hline$C Y P 1 B 1$ 432AA x ABCB1 3435TT & $16(16.0)$ & $11(7.3)$ & $4.68(0.03)^{*}$ & $2.41(1.07-5.43)$ \\
\hline$C Y P 2 C 9$ 1075AA x CYP3A4 664TC & $2(2.0)$ & $13(8.7)$ & $4.73(0.03)^{*}$ & $0.22(0.05-0.97)$ \\
\hline$C Y P 3 A 4$ 664TT x CYP3A5 6986AA & $91(91.0)$ & $120(80.0)$ & $5.51(0.02)^{*}$ & $2.53(1.14-5.59)$ \\
\hline
\end{tabular}

*- статистически достоверные ассоциации

* - statistic significant associations

На следующем этапе работы нами проанализировано влияние ассоциаций парных сочетаний генотипов полиморфных вариантов генов-кандидатов на риск формирования изолированного ДМЖП и раздельно у лиц мужского и женского пола. 
Стратифицированный анализ по полу комбинаций полиморфных вариантов генов ФБК, проводившийся в группах, где мальчики с ДМЖП сравнивались с отцами, а девочки с ДМЖП с матерями представлен в таблице 4.

Распределение частот парных сочетаний генотипов генов ФБК в группах больных ДМжП и здоровых индивидов в зависимости

Таблица 4

\section{от пола (абс, \%)}

Table 4

Frequency distribution of paired combinations of genotypes of FBK genes in groups of patients with VSD and healthy individuals depending on gender (abs, \%)

\begin{tabular}{|c|c|c|c|c|c|c|c|}
\hline \multirow[t]{2}{*}{ Комбинации генотипов } & \multicolumn{2}{|c|}{$\begin{array}{c}\text { Больные } \\
\text { ДМЖП }\end{array}$} & \multicolumn{2}{|c|}{ Контроль } & \multicolumn{2}{|c|}{$\begin{array}{l}\text { Критерий } \\
\text { различия }\end{array}$} & \multirow{2}{*}{$\begin{array}{c}\text { OR } \\
(95 \% \mathrm{CI})\end{array}$} \\
\hline & $\mathrm{n}$ & $\%$ & $\mathrm{n}$ & $\%$ & $\chi^{2}$ & (p) & \\
\hline \multicolumn{8}{|c|}{ Муж. $(\mathrm{n}=40)$ Отцы $(\mathrm{n}=50)$} \\
\hline CYP1B 1432AA x NAT2 590GG & 12 & 30.0 & 6 & 11.5 & 4.90 & $0.03 *$ & $3.29(1.11-9.74)$ \\
\hline$N A T 2590$ GA x ABCB1 3435CT & 9 & 22.5 & 22 & 44.0 & 4.55 & $0.03 *$ & $0.37(0.15-0.94)$ \\
\hline $\begin{array}{l}C Y P 1 B 1432 \mathrm{AA} \times C Y P 2 C 9 \\
1075 \mathrm{AA}\end{array}$ & 11 & 27.5 & 24 & 48.0 & 3.93 & $0.05 *$ & $0.40(0.17-1.00)$ \\
\hline CYP1B1 432GG x CYP3A4 664TT & 9 & 22.5 & 1 & 2.0 & 9.46 & $\begin{array}{c}0.002 \\
*\end{array}$ & $\begin{array}{c}14.23(1.72- \\
117.86)\end{array}$ \\
\hline $\begin{array}{l}\text { CYP3A4 664TT х CYP3A5 } \\
\text { 6986AA }\end{array}$ & 38 & 95.0 & 40 & 80.0 & 4.33 & $0.04 *$ & $4.75(0.98-23.10)$ \\
\hline \multicolumn{3}{|c|}{ Жен. $(n=60)$} & \multicolumn{5}{|c|}{ Матери $(n=100)$} \\
\hline CYP1B1 432AG x NAT2 590AA & 10 & 16.7 & 7 & 7.0 & 3.69 & $0.05 *$ & $2.66(0.95-7.41)$ \\
\hline $\begin{array}{l}C Y P 2 C 91075 \mathrm{AC} \times C Y P 3 A 4 \\
664 \mathrm{TC}\end{array}$ & 4 & 6.7 & 1 & 1.0 & 3.98 & $0.05 *$ & $7.07(0.77-64.83)$ \\
\hline $\begin{array}{l}\text { CYP2C9 1075ACx } \\
\text { CYP3A56986AA }\end{array}$ & 5 & 8.3 & 20 & 20.0 & 3.87 & $0.05 *$ & $0.36(0.13-1.03)$ \\
\hline
\end{tabular}

*- статистически достоверные различия

* - statistic significant differences

Из 8 выявленных комбинаций генотипов, имеющих статистическую достоверность 5 имели повышенный риск формирования ДМЖП: СYР1B 1432AА х NAT2 590GG, CYP1B1 432GG $\mathrm{x}$ CYP3A4 664TT, CYP3A4 664TT x CYP3A5 6986АА - для лиц мужского пола, CYP1B1 432AG x NAT2 590AA, CYP2C9 1075AC x CYР3A4 664ТС - для лиц женского пола, с показателями $\quad(\mathrm{p}<0.05, \quad \mathrm{OR}=3.29, \quad 95 \%$ $\mathrm{CI}=1.11-9.74), \quad(\mathrm{p}<0.05, \quad \mathrm{OR}=14.23, \quad 95 \%$ $\mathrm{CI}=1.72-117.86), \quad(\mathrm{p}<0.05, \quad \mathrm{OR}=4.75, \quad 95 \%$ $\mathrm{CI}=0.98-23.10), \quad(\mathrm{p}<0.05, \quad \mathrm{OR}=2.66, \quad 95 \%$ $\mathrm{CI}=0.95-7.41), \quad(\mathrm{p}<0.05, \quad \mathrm{OR}=7.07, \quad 95 \%$ $\mathrm{CI}=0.77-64.83) \quad$ соответственно и 3 комбинации протективного характера NAT2 590GA x ABCB1 3435CT $(\mathrm{p}<0.05, \mathrm{OR}=0.37$,
95\% $\quad \mathrm{CI}=0.15-0.94), \quad C Y P 1 B 1 \quad 432 \mathrm{AA} \quad \mathrm{x}$ CYP2C9 1075AA $\quad(\mathrm{p}<0.05, \quad \mathrm{OR}=0.40, \quad 95 \%$ $\mathrm{CI}=0.17-1.00)$ - для лиц мужского пола, CYP2C9 1075AC x CYP3A56986AA $(\mathrm{p}<0.05$, $\mathrm{OR}=0.36,95 \% \quad \mathrm{CI}=0.13-1.03) \quad-$ для лиц женского пола.

Нами проведено изучение полиморфных вариантов генов ФБК на этнически гомогенной выборке русских жителей Краснодарского края больных врожденным изолированным ДМЖП. Основываясь на данные научной литературы, мы предположили, что полиморфизмы Val432Leu CYP1B1, G590A NAT2, 3435T ABCB1, A1075C CYP2C9, T664C CYP3A4, +6986G/A CYP3A5, как гены ФБК могут быть ассоциированы с 
развитием врожденного изолированного ДМЖП.

Заключение. Таким образом, при анализе парных сочетаний полиморфных вариантов генов ФБК установлены 8 статистически значимых ассоциаций с риском развития ДМПП: 4 из них ассоциировалась с повышенным риском порока, а 4, напротив, ассоциировалась с пониженным риском изучаемого ВПР СК. Результаты, полученные при анализе межгенных комбинаций посредством оценки ассоциаций парных сочетаний генотипов ФБК, демонстрируют их тесное взаимодействие, что отражает вовлеченность различных метаболических путей детоксикации ксенобиотиков. Учитывая относительно малочисленность обследованных групп и потенциальную вовлеченность других генов ФБК в развитие ДМЖП, для разработки модели прогнозирования риска развития порока в рамках медикогенетического консультирования и пренатальной диагностики супружеских пар с отягощенным семейным анамнезам необходим дальнейший поиск молекулярногенетических маркеров.

В отношении данной статьи не было зарегистрировано конфликта интересов.

\section{Список литературы}

1. Врожденные пороки сердца: распространенность в популяции, факторы риска / А.В. Богачева [и др.] // Мать и дитя в Кузбассе. 2012. N 1. С. 19-24.

2. Динамика частоты врожденных пороков развития в РФ (по данным федеральной базы мониторинга ВПР за 2006-2012 гг.) / Н.С. Демикова [и др.] // Российский вестник перинатологии и педиатрии. 2015. N 2. С. 72-77.

\section{3. Особенности}

эпидемиологии врожденных пороков сердца у детей г. Кемерово как крупного промышленного центра / A.В. Шабалдин [и дp.] // Комплексные проблемы сердечно-сосудистых заболеваний. 2014. N 4. C. $38-46$.

4. Врожденные аномалии (пороки) системы кровообращения у населения России и их оперативное лечение (2005-2014 годы) / Л.А. Бокерия [и др.] // Грудная и сердечнососудистая хирургия. 2016. N 4. С. 202-206.
5. Лазарев К.Ю., Голубцов В.И. Анализ структуры и распространенности изолированных врожденных пороков развития системы кровообращения среди новорожденных Краснодарского края (по результатам мониторинга 1998-2009 гг.) // Кубанский научный медицинский вестник. 2010. Т. 2, N 125. C. 95-100.

6. Влияние социальных, медицинских и экологических факторов на формирование спорадических врожденных пороков сердца / А.В. Шабалдин [и др.] // Российский вестник перинатологии и педиатрии. 2018. Т. 63, N 1. C. 14-21.

7. Glutathione S-transferase genes and the risk of type 2 diabetes mellitus: Role of sexual dimorphism, gene-gene and gene-smoking interactions in disease susceptibility / I. Azarova [et al.] // J Diabetes. 2018. Vol. 10(5). P. 398-407. doi: 10.1111/1753-0407.12623.

8. Robert A.M. Tacrolimus pharmacokinetics and pharmacogenetics: influence of adenosine triphosphate-binding cassette B1 $(A B C B 1)$ and cytochrome (CYP) $3 A$ polymorphisms // Fundamental and clinical pharmacology. 2007. Vol. 21(4). P. 427-435.

9. Saab Y.B., Robert A.M., Langaee T. Genetic Polymorphisms of CYP2C9: Comparison of Prevalence in the Lebanese Population with Other Populations // Pharmacology \& Pharmacy. 2011. N 2. P. 88-93.

10.The contribution of CYP2C gene subfamily involved in epoxygenase pathway of arachidonic acids metabolism to hypertension susceptibility in Russian population / A. Polonikov [et al.] // Clin Exp Hypertens. 2017. Vol. 39(4). P. 306-311. doi: 10.1080/10641963.2016.1246562.

11.Haiyan J. Association of CYP1B1 Polymorphisms with breast cancer: a case-control study in the han population in ningxia hui autonomous region, P.R. China // Biomarker insights. 2010. N 5. P. 21-27.

12.A Novel Polymorphism in the Promoter of the CYP4A11 Gene Is Associated with Susceptibility to Coronary Artery Disease / S. Sirotina [et al.] // Dis Markers. 2018. P. 5812802. doi: $10.1155 / 2018 / 5812802$.

13.Polymorphisms of CYP2C8, CYP2C9 and CYP2C19 and risk of coronary heart disease in Russian population / A. Polonikov [et al.] // Gene. 2017. N 627. P. 451-459. doi: 10.1016/j.gene.2017.07.004. 
14.Cotoa,e E. Functional polymorphisms in the CYP3A4, CYP3A5, and CYP21A2 genes in the risk for hypertension in pregnancy // Biochemical and biophysical research communications. 2010. Vol. 397(3). P. 576-579.

15.Chamorro J.G. The distribution of allelic and genotypic frequencies of N-Acetyltransferase-2 variants in an Argentine population // J infect dev ctries. 2012. Vol. 6(9). P. 671-674.

16.Реброва О.Ю. Статистический анализ медицинских данных. Применение пакета прикладных программ STATISTICA. М.: Медиа Cфера, 2002. 312 c.

\section{References}

1. Bogacheva EV, Antonov OV, Artyukova SI, et al. [Congenital heart diseases: prevalence in the population, risk factors]. Mat' $\mathrm{i}$ ditya v Kuzbasse. 2012;1:19-24. Russian.

2. Demikova NS, Lapina AS, Podol'naya MA, et al. [The dynamics of the frequency of congenital malformations in the Russian Federation (according to the data of the Federal Monitoring Base of the VPR for 2006-2012)]. Rossiyskiy vestnik perinatologii i pediatrii. 2015;2:72-77. Russian.

3. Shabaldin AV, Glebova LA, Bachina $\mathrm{AV}$, et al. [Peculiarities of epidemiology of congenital heart disease in children of Kemerovo as a large industrial center]. Kompleksnyye problemy serdechno-sosudistykh zabolevaniy. 2014;(4):3846. Russian.

4. Bokeriya LA, Stupakov IN, Gudkova $\mathrm{RG}$, et al. [Congenital anomalies (defects) of the circulatory system in the Russian population and their surgical treatment (2005-2014)]. Grudnaya i serdechno-sosudistaya khirurgiya. 2016;4:202-206. Russian.

5. Lazarev KYu, Golubtsov VI. [Analysis of the structure and prevalence of isolated congenital malformations of the circulatory system among infants of the Krasnodar Territory (based on monitoring results of 1998-2009)]. Kubanskiy nauchnyy meditsinskiy vestnik. 2010;2(125):95100. Russian.

6. Shabaldin AV, Tsepokina AV, Shmulevich SA, et al. [Influence of social, medical and environmental factors on the formation of sporadic congenital heart defects]. Rossiyskiy vestnik perinatologii i pediatrii. 2018;63(1):14-21. Russian.
7. Azarova I, Bushueva O, Konoplya A, et al. Glutathione S-transferase genes and the risk of type 2 diabetes mellitus: Role of sexual dimorphism, gene-gene and gene-smoking interactions in disease susceptibility. J Diabetes. 2018 May;10(5):398-407. doi: 10.1111/17530407.12623 .

8. Robert AM. Tacrolimus pharmacokinetics and pharmacogenetics: influence of adenosine triphosphate-binding cassette B1 $(A B C B 1)$ and cytochrome (CYP) $3 A$ polymorphisms. Fundamental and clinical pharmacology. 2007;21(4):427-435.

9. Saab YB, Robert AM, Langaee T. Genetic Polymorphisms of CYP2C9: Comparison of Prevalence in the Lebanese Population with Other Populations. Pharmacology \& Pharmacy. 2011;2:88-93.

10. Polonikov A, Bykanova $\mathrm{M}$, Ponomarenko I, et al. The contribution of CYP2C gene subfamily involved in epoxygenase pathway of arachidonic acids metabolism to hypertension susceptibility in Russian population. Clin Exp Hypertens. 2017;39(4):306-311. doi: 10.1080/10641963.2016.1246562.

11. Haiyan J. Association of CYP1B1 Polymorphisms with breast cancer: a case-control study in the han population in ningxia hui autonomous region, P.R. China. Biomarker insights. 2010;5:21-27.

12. Sirotina S, Ponomarenko I, Kharchenko A, et al. A Novel Polymorphism in the Promoter of the CYP4A11 Gene Is Associated with Susceptibility to Coronary Artery Disease. Dis Markers. 2018 Feb 1;2018:5812802. doi: $10.1155 / 2018 / 5812802$.

13. Polonikov A, Kharchenko A, Bykanova $\mathrm{M}$, et al. Polymorphisms of CYP2C8, CYP2C9 and CYP2C19 and risk of coronary heart disease in Russian population. Gene. 2017 Sep 5;627:451459. doi: 10.1016/j.gene.2017.07.004.

14. Cotoa,e E. Functional polymorphisms in the CYP3A4, CYP3A5, and CYP21A2 genes in the risk for hypertension in pregnancy. Biochemical and biophysical research communications. 2010;397(3):576-579.

15. Chamorro JG. The distribution of allelic and genotypic frequencies of N-Acetyltransferase-2 variants in an Argentine population. $J$ infect dev ctries. 2012;6(9):671-674.

16. Rebrova OYu. [Statistical analysis of medical data. Application of the STATISTICA software package]. M.: Media Sfera; 2002. Russian. 
Константин Юрьевич Лазарев, кандидат медицинских наук, доцент, кафедра биологии с курсом медицинской генетики, ФГБОУ ВО «Кубанский государственный медицинский университет».

Ольга Павловна Брайко, кандидат биологических наук, ассистент, кафедра биологии с курсом медицинской генетики, ФГБОУ ВО «Кубанский государственный медицинский университет».
Konstantin Yu. Lazarev, Candidate of Medical Sciences, Associate Professor, Department of Biology with a Course in Medical Genetics, Kuban State Medical University.

Olga P. Braiko, Candidate of Biological Sciences, Assistant, Department of Biology with a Course in Medical Genetics, Kuban State Medical University.

Статья поступила в редакцию 6 апреля 2018 г. Receipt date 2018 April 6. 